\title{
COVID-19 sends STEMI to quarantine!?
}

\author{
Seifollah Abdi ${ }^{1}$. Mojtaba Salarifar ${ }^{2} \cdot$ Seyedeh Hamideh Mortazavi ${ }^{2} \cdot$ Parham Sadeghipour $^{1} \cdot$ Babak Geraiely $^{3}$ (])
}

Received: 24 April 2020 / Accepted: 5 May 2020 / Published online: 20 May 2020

(c) Springer-Verlag GmbH Germany, part of Springer Nature 2020

Sirs,

In December 2019, severe acute respiratory syndrome Coronavirus 2 (SARS-COV-2), termed "novel COVID-19", emerged in China and was considered a pandemic by the World Health Organization (WHO) on March 11, 2020 [1]. So far, a sizable population of the world has been affected [2] and many have expired. Although an epidemic necessitates the organization of medical and health facilities to control the crisis, the provision of services to other patients, who may have serious conditions, should not be neglected because of the catastrophic consequences.

In Iran, 24/7 primary percutaneous coronary intervention (PCI) as the standard treatment strategy for patients with ST-elevation myocardial infarction (STEMI) [3-7] was launched in September 2015 to achieve a fair distribution of healthcare resources. Currently, 49 general and heart hospitals provide these services, with 48915 patients having undergone primary PCI thus far.

With the outbreak of the Coronavirus, the first case of COVID-19 was officially reported on February 19, 2020. As is shown in Fig. 1, we have found a significant drop

Babak Geraiely

bgeraiely@sina.tums.ac.ir

Seifollah Abdi

abdiseifollah@gmail.com

Mojtaba Salarifar

mojtabasalarifar@yahoo.com

Seyedeh Hamideh Mortazavi

h-mortazavi@student.tums.ac.ir

Parham Sadeghipour

psadeghipour@hotmail.com

1 Rajaie Cardiovascular Medical and Research Center, Iran University of Medical Sciences, Tehran, Iran

2 Tehran Heart Center, Tehran University of Medical Sciences, Tehran, Iran

3 Imam Khomeini Hospital Complex, Tehran University of Medical Sciences, Keshavarz Boulevard, P.O. Box: 1419733141, Tehran, Iran (approximately 25-40\%) in the number of documented STEMI patients who have undergone primary PCI in our 24/7 primary PCI-capable hospitals.

What may be responsible for this decline is patients' fear of contamination with the Coronavirus in hospitals or the exhaustion of the entire health system resources by COVID19 patients. On the other hand, the manifestation of critical STEMI with dyspnea and pulmonary edema could be mistaken with the Coronavirus features, resulting in the management of the patient as a COVID-19 case from the outset. In the worst-case scenario, the patient might expire at home due to a wasted time interval between the symptom onset and the first medical contact.

According to recent reports [8-10], the number of patients undergoing primary PCI and acute coronary syndrome admissions have also dropped significantly in other countries. Indubitably, this is an extremely worrying issue with adverse long-term consequences for patients and healthcare systems.

We suggest that the general population be fully informed as regards the symptoms of STEMI by social media. We also herewith underscore the vital importance of timely referrals to designated hospitals. Moreover, STEMI patients highly suspicious of COVID-19 should be isolated and screened via laboratory and imaging tests, and the medical staff should use full personal protective equipment (PPE).

\section{Availability of data and material}

All data generated or analyzed during this study are included in this published article. 
Fig. 1 Trend of primary percutaneous coronary intervention in general and heart hospitals in the fall and winter of the last 2 years

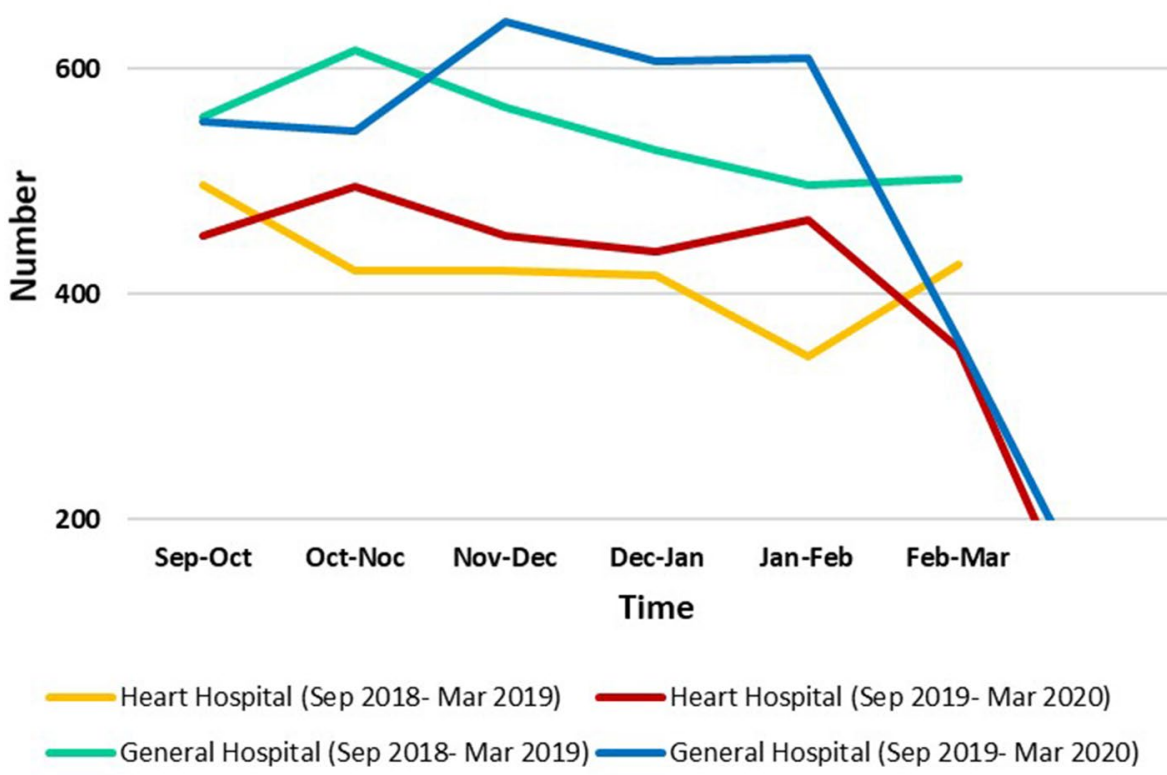

Author contributions Conception or design of the work: SA, MS, SHM, PS, BG. Supervision of development of the work: SA, MS, PS, BG. Provision of study materials or patients and statistical expertise: SHM, PS, BG. Drafting of the article: SHM, PS, BG. Critical revision of the article for important intellectual content: SA, MS, SHM, PS, BG. Administrative, technical, or logistic support: SA, MS, BG. Final approval of the article: SA, MS, SHM, PS, BG.

Funding None.

\section{Compliance with ethical standards}

Conflict of interest We declare no conflict of interest.

\section{References}

1. Bedford J, Enria D, Giesecke J, Heymann DL, Ihekweazu C, Kobinger G, Lane HC, Memish Z, Oh M-D, Schuchat A (2020) COVID-19: towards controlling of a pandemic. Lancet 28(395):1015-1018. https://doi.org/10.1016/S0140 $-6736(20) 30673-5$

2. WHO (2020) Coronavirus disease 2019 (COVID-19) Situation Report-77. 28(395):1015-8

3. Widimsky P, Wijns W, Kaifoszova Z (2012) Stent for Life: how this initiative began? Eurointervention: J EuroPCR Collab Work Group Interv Cardiol Eur Soc Cardiol 8: 8-10. 10.4244/ EIJV8SPA3

4. Zahler D, Lee-Rozenfeld K, Ravid D, Rozenbaum Z, Banai S, Keren G, Shacham Y (2019) Relation of lowering door-to-balloon time and mortality in ST segment elevation myocardial infarction patients undergoing percutaneous coronary intervention. Clin Res Cardiol 108(9):1053-1058. https://doi.org/10.1007/s00392-01901438-6

5. Reindl M, Tiller C, Holzknecht M, Lechner I, Eisner D, Riepl L, Pamminger M, Henninger B, Mayr A, Schwaiger JP, Klug G, Bauer A, Metzler B, Reinstadler SJ (2020) Global longitudinal strain by feature tracking for optimized prediction of adverse remodeling after ST-elevation myocardial infarction. Clin Res Cardiol. https://doi.org/10.1007/s00392-020-01649-2

6. Feistritzer HJ, Jobs A, de Waha-Thiele S, Eitel I, Freund A, AbdelWahab M, Desch S, Thiele H (2020) Multivessel versus culpritonly PCI in STEMI patients with multivessel disease: meta-analysis of randomized controlled trials. Clin Res Cardiol. https://doi. org/10.1007/s00392-020-01637-6

7. Jäger B, Haller PM, Piackova E, Kaff A, Christ G, Schreiber W, Weidinger F, Stefenelli T, Delle-Karth G, Maurer G, Huber K, Vienna SRG (2020) Predictors of transportation delay in patients with suspected ST-elevation-myocardial infarction in the VIENNA-STEMI network. Clin Res Cardiol Off J German Cardiac Soc 109(3):393-399. https://doi.org/10.1007/s00392-01901520-z

8. Metzler B, Siostrzonek P, Binder RK, Bauer A, Reinstadler SJ (2020) Decline of acute coronary syndrome admissions in Austria since the outbreak of COVID-19: the pandemic response causes cardiac collateral damage. Eur Heart J. https://doi.org/10.1093/ eurheartj/ehaa314

9. Thornton J (2020) Covid-19: A and E visits in England fall by $25 \%$ in week after lockdown. BMJ 369:m1401. https://doi.org/10.1136/ bmj.m1401

10. Rosenbaum L (2020) The untold toll - the pandemic's effects on patients without Covid-19. N Engl J Med. https://doi.org/10.1056/ NEJMms2009984 